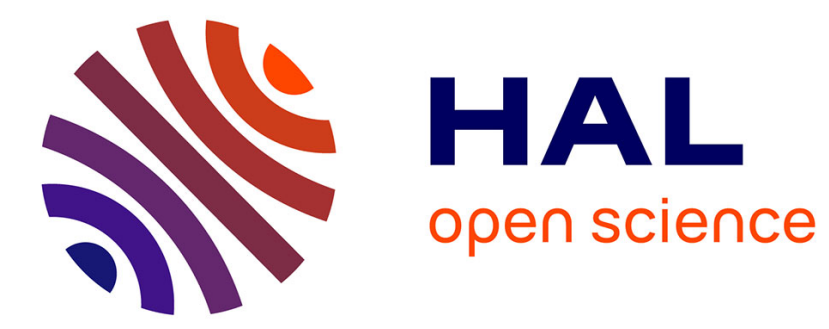

\title{
THE AEROGEL GLASS CONVERSION
}

\author{
J. Phalippou, T. Woignier, M. Prassas
}

\section{To cite this version:}

J. Phalippou, T. Woignier, M. Prassas. THE AEROGEL GLASS CONVERSION. Journal de Physique Colloques, 1989, 50 (C4), pp.C4-47-C4-52. 10.1051/jphyscol:1989408 . jpa-00229483

\section{HAL Id: jpa-00229483 https://hal.science/jpa-00229483}

Submitted on 1 Jan 1989

HAL is a multi-disciplinary open access archive for the deposit and dissemination of scientific research documents, whether they are published or not. The documents may come from teaching and research institutions in France or abroad, or from public or private research centers.
L'archive ouverte pluridisciplinaire HAL, est destinée au dépôt et à la diffusion de documents scientifiques de niveau recherche, publiés ou non, émanant des établissements d'enseignement et de recherche français ou étrangers, des laboratoires publics ou privés. 
REVUE DE PHYSIQUE APPLIQUEE

Colloque C4, Supplément au $n^{\circ} 4$, Tome 24, Avril 1989

\title{
THE AEROGEL GLASS CONVERSION
}

\author{
J. PHALIPPOU, T. WOIGNIER and M. PRASSAS* \\ Laboratoire de Science des Matériaux vitreux, Université des Sciences \\ et Techniques du Languedoc, F-34060 Montpellier Cedex 2, France \\ *Corning Europe, 7 avenue de Valvins, F-77210 Avon, France
}

\begin{abstract}
Résumé - Les divers traitements qui permettent de transformer un aérogel de silice en verre sont examinés. La monolithicité des aérogels peut être obtenue par évacuation hypercritique du méthanol ou du $\mathrm{CO}_{2}$. Ces deux voies ont été successivement utilisées et des comparaisons sur 1a structure de 1'aérogel obtenu sont précisées. Les aérogels obtenus par évacuation hypercritique du méthanol sont hydrophobes. Le traitement d'oxydation permet d'obtenir des aérogels ne contenant plus de résidus carbonés. La température de frittage dépend de la nature de $1^{\prime}$ aérogel et est fonction de la teneur en eau. Nous montrons que l'eau joue un rôle très important dans les phénomènes de moussage et de cristallisation observés. Un traitement de chloration permet d'obtenir des verres de silice exempts d'eau de structure.
\end{abstract}

\begin{abstract}
The different treatments which have been carried out to transform an aerogel into a glass are reviewed. Monolithicity of aerogels can be reached using hypercritical drying of methanol or $\mathrm{CO}_{2}$. These two ways are investigated and comparisons about the structure of the aerogels are deduced. Aerogels obtained from methanol hypercritical evacuation are hydrophobic. The oxidation treatment gives rise to free carbon aerogels. The sintering temperature depends on the nature of the aerogel and is linked to its hydroxyl content. It is shown that the water content plays a very important role and causes the bloating and the crystallization phenomena, A chlorination treatment of aerogel allows free water silica glass to be obtained,
\end{abstract}

\section{1 - INTRODUCTION}

Aerogels, as obtained, may be used for various applications. On the other hand, there are a lot of fundamental works devoted to these highly porous materials which have been demonstrated to be fractal. However aerogels may also be regarded as initial compounds to further elaboration processes. Due to their very fine structure, aerogel powders show a great tendency to densify at very low temperatures. The sintering of cordierite obtained from aerogel has been reported /1/. Some attempts in the laboratory show that a similar way is available for a ceramic oxide whose composition is close to that of mullite. A such advantage applies both to amorphous aerogels and to aerogels which are then submitted to a crystallization heat treatment.

Nevertheless the most important advantage of the hypercritical drying process concerns the possibility to get monolithic aerogels. In that case the sintering can be performed by a simple heat treatment without any grinding, compaction or other polluting treatments.

In such a way the monolith will be partially densified or totally densified in respect with required application.

A partially densified aerogel is a host material (1ike a sponge) and then it may be impregnated with numerous active molecules chosen showing specific properties.

Total densification is hard to realize for aerogels which undergo a sudden phase transformation when the temperature increases. ZrO2 aerogels fall within that class of materials. The crystallization provokes a volume change which usually induces the cracking of the partially crystallized aerogels. Crystallization phenomenon has to be carefully controlled.

This paper is more particularly devoted to silica aerogels which remain amorphous during the sequency of heat treatments allowing the densification to be achieved. 


\section{2 - PROPERTIES UF SILICA AEROGELS}

Monolithic silica aerogels are mainly obtained by two ways :

hypercritical drying of a liquid mixture $\mathrm{H}_{2} \mathrm{O}$-alcohol or $\mathrm{CO}_{2}$. These two ways were investigated $12 \%$. The structures of aerogels are very similar. The vibrational spectra of the same sample deshydrated using the two above mentionned ways are shown on figure 1 .

The most important difference comes from the effect of the esterification reaction which occurs in the autoclave when the solvent is an alcoholic medium. Due to that reaction the aerogel becomes "hydrophobic". The hydrophobicity is linked to the presence of organic radicals which replace the most part of the free silanols groups.

Usually a xerogel has about 5 to 6 silanol groups per $\mathrm{nm}^{2}$. After an esterification treatment, specific surface area measurements and microanalysis show that the number of $0 R$ groups $/ \mathrm{nm}^{2}$ (ethoxy or methoxy) varies between 2 and 3 depending on the duration and the temperature of treatment $/ 3 /$. This number can reach a value of five $0 \mathrm{Me} / \mathrm{nm}^{2}$ if the esterification is carried out at $500^{\circ} \mathrm{C}$ with methanol vapor $/ 4 /$.

It is noteworthy that the IR spectra shows that silica aerogels contain an appreciable amount of silanols groups although they are hydrophobic. Internal silanols whose the absorption band is situated at $3660 \mathrm{~cm}^{-1}$ cannot be esterified during the autoclave treatment.

$\mathrm{CO}_{2}$ aerogels are less hydrophobic. If no precaution is taken, this sort of aerogels will again react with atmospheric water. Capillary condensation may occur which sometimes give rise to capillary stresses leading to cracking of the aerogel. For all these features we believe that it is more convenient to use hydrophobic aerogel as starting material for conversion into a massive silica glass.
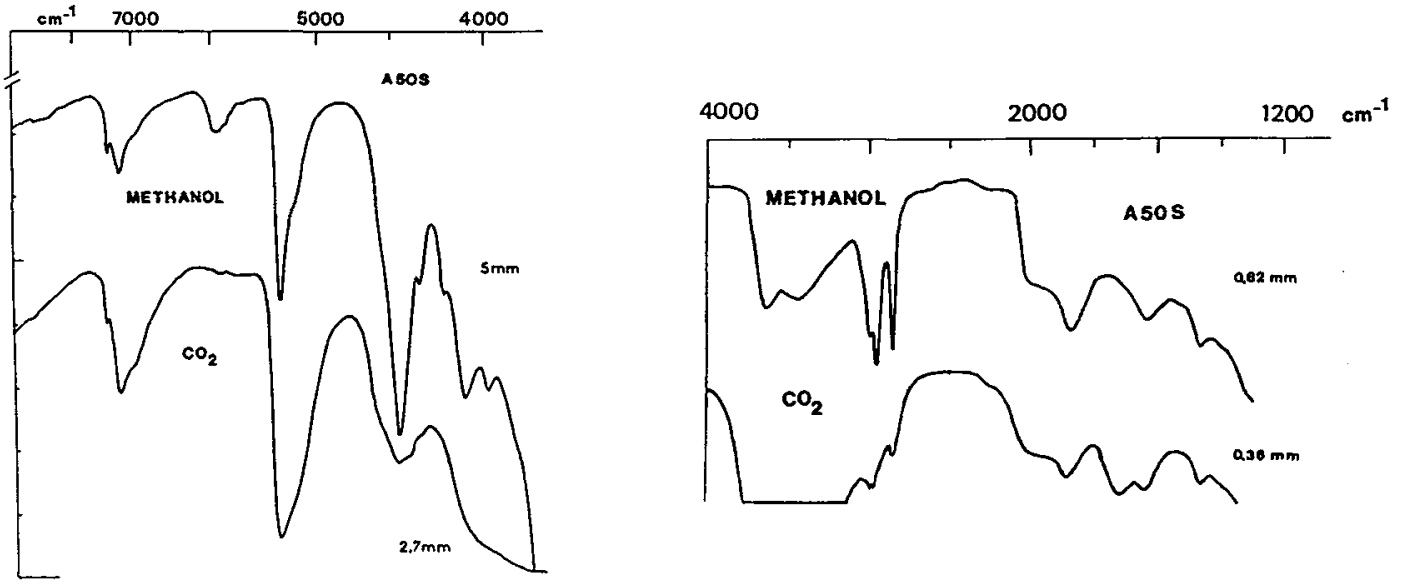

Fig. 1 - Structural comparison of silica aerogels dried using different solvents evacuations.

\section{3 - THERMAL TREATMENTS BEFORE SINTERING}

The thermal treatments performed before sintering are carried out to remove the organic residues beared by the aerogel. The oxidation reaction may be followed using various techniques. GTA shows a weigth loss of about 5-10\% depending on the aerogel composition.

DTA confirms that oxidation reaction is an exothermic phenomenon which appears between 300 and $500^{\circ} \mathrm{C}$. A detailed analysis of structural modification was carried out using IR spectroscopy on thin slide of aerogel. The study shows that organic residues react with air and give rise to new silanol groups. Silanol groups condense together and create siloxane bonds /5/. As a consequence the Young's modulus of aerogels increases $/ 6 /$ and the skeletal density measured by helium pycnometry becomes close to that of the silica glass 17/. Moreover the last measurements confirm that the porosity of aerogel remains totally open during the oxidation process provided that treatment is conducted at low temperature.

Raman spectra of silica aerogels shows the presence of "defect" bands (480 and $600 \mathrm{~cm}^{-1}$ ) whose the exact assignment is not well established. In usual xerogels these bands are due to cyclic arrangments of siloxane bonds. The cyclic arrangments would induce an increase of the skeletal density which has been shown higher than $2.2 / 8 /$. 
Cross polarisation NMR experiments are in progress to better understand the Raman lines evolution as a function of temperature.

\section{4 - AEROGEL EVOLUTION DURING THE SINTERING STAGE}

The structural evolution of the aerogel as a function of temperature is shown on figure 2. The absorption bands are mainly due to silanols and siloxane groups. As the temperature increases the water content decreases. The initial oxided aerogel is quite transparent. It becomes opaque as the sintering progresses. Diffusion phenomenon accounts for this behavior. The aerogel becomes again transparent during the last instants of the sintering.

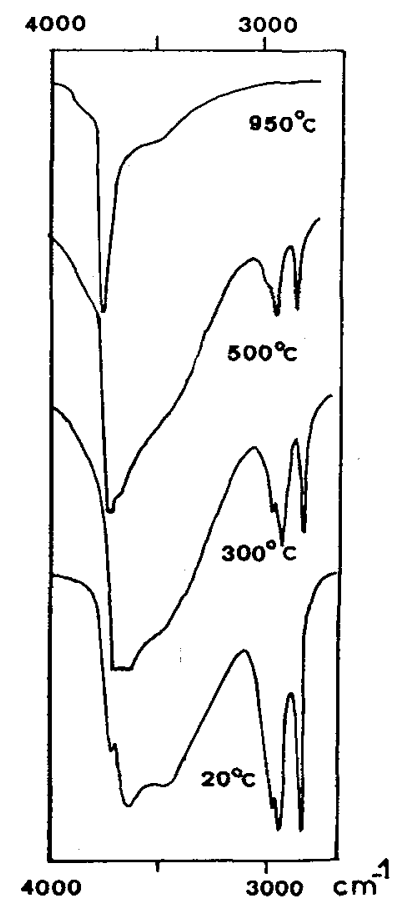

Fig. 2 - Structural evolution of a silica aerogel as a function of temperature.

The partially densified aerogel can be transformed into a transparent one by impregnating with a liquid solution whose the refractive index is close to that of the silica glass.

The diffusion intensity is then a measurement of interest for the evaluation of close porosity or porosity non accessible by liquid solution $/ 9 /$.

The sintering of aerogel is followed by various techniques. It always occurs suddenly in a short range of temperature. We have previously shown that the sintering kinetic depends on numerous parameters linked to the starting material. The extent of hydrolysis, the catalyst nature and dilution are among the most important parameters. On the other hand the water or alkali content play a very important role on aerogel-glass conversion (Fig. 3 ). 

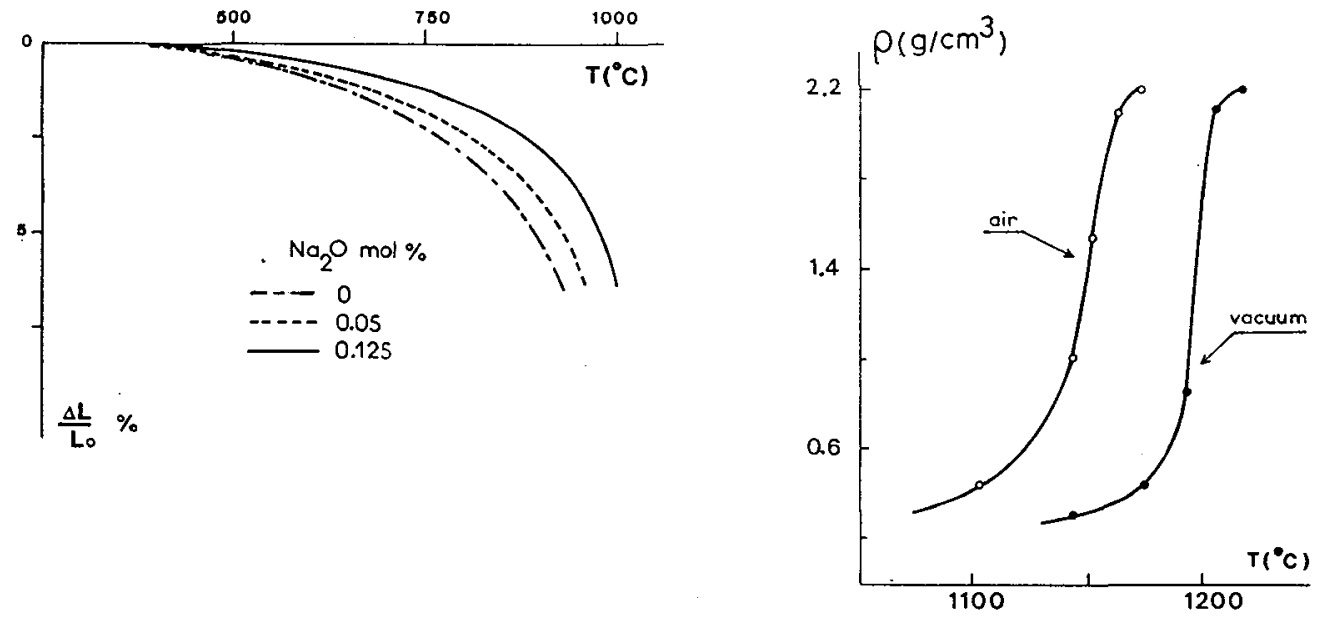

Fig. 3 - Effect of alkali content (1 inear shrinkage) and water content (a : $5000 \mathrm{ppm}$ b : $800 \mathrm{ppm}$ ) on sintering behaviour.

Figure 4 shows the evolution of the specific surface area and the linear dimension change of a A60S aerogel. The textural properties of the aerogel do not vary up to 900 $950^{\circ} \mathrm{C}$. Above this temperature range the sintering happens very quickly. The linear shrinkage of the sample is then about $50 \%$. The totally densified material is transparent and exbibits physical properties analogous to that of the usual silica glass.

The analysis of the sintering mechanism has been performed using isothermal dilatometric measurements. At low temperatures, the sintering is of small amplitude due to a diffusional mechanism. At higher temperatures the sintering appears due to a viscous flow phenomenon $/ 10 /$.

However the obtained glasses have a high water content (1000-5000ppm) as measured by IR spectroscopy using the intensity of the $2.73 \mu \mathrm{m}$ absorption band. The samples fired at a temperature above $1250^{\circ} \mathrm{C}$ show a bloating effect which leads sometimes to a crystallization phenomenon.

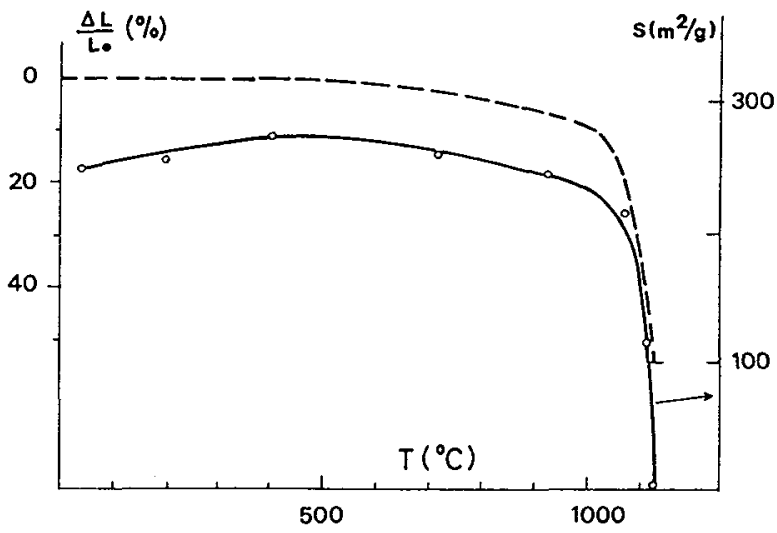

Fig. 4 - Textural properties evolution of a silica aerogel versus temperature. 


\section{5 - FOAMING OF SILICA GLASS}

We have previously shown that the foaming effect is not homogeneous. Bubbles are first located in the core of the sample /11/. This phenomenon is linked to the insulating property of silica. As the temperature increase proceeds a temperature gradiant occurs between the skin and the core of the sample. The surface densification induces the chemical species, which create the foaming effect, to move towards the core. Only the core shows an open porosity.

A rapid sintering induces a premature closure of the pores. Bubble gases are constituted by $\mathrm{H}_{2}, \mathrm{O}_{2}, \mathrm{~N}_{2}, \mathrm{CO}$ and $\mathrm{CO}_{2} / 12 \%$. However we have to point out that air is not alone responsible for the foaming phenomenon.

As observed, sintering under vacuum leads to a glass which bloats again at high temperatures. Even reduced (500 ppm) the water content remains very high. A spectroscopic study 113/ shows that the water content of the glass is higher in the core.

The foaming effect has been investigated in some extent and we have shown that the Mackenzie and Shuttleworth's model can explain both the sintering and the foaming effect depending on the nature of gas inside the pores. Foaming is linked to the diffusive property of the gas. Assuming that the gas is the foaming agent we have performed experiments to decrease the water content of glasses obtained from aerogels /11/.

There are mainly two manners to reduce the water content in glasses: nitridation or halogenation. Halogenation is the most convenient, it is usually carried out using chloride agents such as $\mathrm{Cl}_{2}, \mathrm{SOCl}_{2}, \mathrm{CCl}_{4}$. The last compound was chosen because the chlorination reaction is complete, it occurs at low temperature and does not affect siloxane bonds.

The chlorination of aerogels was performed at $500^{\circ} \mathrm{C}$ for 15 to 60 minutes. The obtained glasses do not foam in the temperature range between $1400-1500^{\circ} \mathrm{C}$ and they are free of water $(<\mathrm{lppm})$.

However the sintering must be carried out inside the same furnace (allowing the chlorination treatment) to avoid the hydrolysis of $\mathrm{Si}-\mathrm{Cl}$ bonds.

If the duration of chlorination treatment is too long it is possible to observe another foaming phenomenon which occurs at very high temperatures $\left(1800-2000^{\circ} \mathrm{C}\right)$. This new foaming effect comes from chlorine gas which is released.

It can be prevented by treating the aerogel under oxygen to remove $\mathrm{Si}-\mathrm{Cl}$ groups. These gas species are diluted into a high diffusive gas such as helium.

Some authors prefer to perform a halogenation treatment using fluoride compounds. The $\mathrm{Si}-\mathrm{F}$ is stronger than $\mathrm{Si}-\mathrm{Cl}$ bond and on an another hand it is well known that $\mathrm{Si}-\mathrm{F}$ bond is hydrophobic. However the fluorination treatment can induce a depolymerization of the silica network.

In the case of gels an elegant manner to introduce fluoride element consists of gelifying the solution under HF catalyst conditions. The gel and as a consequence the aeroge 1 contain Si-F bonds. They are easily dehydrated and for some of them no foaming is observed $/ 14 /$.

A crystallization phenomenon sometimes occurs at temperatures close to those of foaming. It is also related to the water content of the material. Cristobalite crystals are located in the vitreous phase between the bubbles. The core of the glass crystallizes before the surface. This behavior is contrary to that usualiy observed in silica glass. On cooling, the $\beta \rightarrow \alpha$ cristobalite transformation is clearly observed on DTA at about $300^{\circ} \mathrm{C}$ and induces the cracking of the material.

\section{6 - CONCLUSION}

Monolithic aerogels are materials which are easily transformed into glass. Due to their characteristic texture with high specific surface area and open porosity, efficient dehydration treatments can be performed rapidly at low temperature. Sintering takes place in a narrow temperature range but may be controlled as a function of time at lower temperatures. On another hand it is possible to develop a gradient of temperature and as a consequence a pore size difference between the surface and the core. Such particular textures which are easity done may open a new field of applications for silica aerogels.

\section{REFERENCES}

/1/ VESTEGHEM H.,et al., this issue.

12/ WOIGNIER, T., Thesis Montpellier (France) (1984).

/3/ KONDO, S., FUJIWARA, H., OKAZAZI, E., ICHII, T., J. Colloid. and Inter. Science, $\underline{75}$ (1980) 328. 
/4/ ASANO, T., KITAHARA, S., Nippon Kagatu Zasshi, 91 (1970) 109.

/5/ PRASSAS, M., PHALIPPOU, J., ZARZYCKI, J., Glastechn. Ber., 56K (1983) 542.

/6/ WOIGNIER, T., PHALIPPOU, J., VACHER, R., MRS Spring Meeting (Reno) (April 1988) to be published by Material Research Society.

/7/ WOIGNIER, T., PHALIPPOU, J., J. Non-Cryst. Solids, $\underline{93}$ (1987) 17.

/8/ BRINKER, C.J., TALLANT, D.R., ROTH, E.P., ASHLEY, C.S., J. Non-Cryst. Solids, $\underline{82}$ (1986) 117.

19/ SATOH, S., SUSA, K., Matsuyama, I., SUganUMa, T., J. Non-Cryst. Solids, $\underline{55}$ (1983) 455.

/10/ PRASSAS, M., PHALIPPOU, J., ZARZYCKI, J., in "Science of Ceramic Chemical Processing", ed. by HENCH L.L. and ULRICH, D.R., J. Wiley and sons, NY (1986) chap 17.

/11/ PHALIPPOU, J., WOIGNIER, T., ZARZYCKI, J., "UTtrastructure Processing of Ceramics, Glasses and Composites", Ed. HENCH, L.L., ULRICH, D.R., J. Wiley and sons, NY (1984) chap. 7 .

112/ YANAGISAWA, 0., TANAKA, C., KOKUBU, Y., SUZUKI, Y., J. Non-Cryst. Solids, 38-39 (1980) 599.

/13/ WOIgNiER, T., PHALIPPOU, J., Riv. della Staz. Sper. Vetro, $\underline{3}$ (1984) 47.

/14/ ZELLER, R., Thesis Muthouse (France) (1987). 